\title{
RESEARCH
}

\section{CAN THE C-REACTIVE PROTEIN TO ALBUMIN RATIO PREDICT MORTALITY DUE TO HEMIARTHROPLASTY PERFORMED AFTER HIP FRACTURE IN THE ELDERLY POPULATION?}

Turkish Journal of Geriatrics

DOI: 10.31086/tigeri.2021.202

2021; 24(1): 79-86

- Fevzi COŞKUN SÖKMEN ${ }^{1}$

- Coşkun ULUCAKÖY1

CORRESPONDANCE

\section{${ }^{1}$ Coşkun ULUCAKÖY}

Dr Abdurrahman Yurtaslan Oncology Training and Research Hospital, Department of Internal Medicine, Ankara, Turkey

Phone: +905323262305

e-mail: coskunulucakoy@gmail.com

Received: Nov 14, 2020

Accepted: Mar 09, 2021

Dr Abdurrahman Yurtaslan Oncology Training and Research Hospital, Department of Internal Medicine, Ankara, Turkey

${ }^{2}$ Dr Abdurrahman Yurtaslan Oncology Training and Research Hospital, Department of Orthopaedics and Traumatology, Ankara, Turkey

\section{Abstract}

Introduction: Hip fractures are a vital mortality and morbidity problem in the elderly population. This study investigates the role of the c-reactive protein/ albumin ratio in mortality after hip fractures.

Materials and Method: The records of 144 patients ages 65 years and older who underwent hemiarthroplasty for hip fractures between 2015 and 2018 were retrospectively analyzed. Patients' records included age, gender, fracture type, American Society of Anesthesiologists score, the time between fracture and surgery, the time between surgery and discharge, length of hospital stay, preexisting comorbidities, preoperative c-reactive protein and albumin levels, and mortality.

Results: The median age of the patients was 79 years (range: 65-101). Regarding sex, 89 patients (61.8\%) were female, and 55 patients (38.2\%) were male. Based on the univariate analysis, age, comorbidity $\geq 3$, American Society of Anesthesiologists score $\geq 4$, the time between fracture and surgery $\geq 2$ days, the time between surgery and discharge $\geq 5$ days, c-reactive protein $\geq$ $79 \mathrm{mg} / \mathrm{L}$, albumin $<2.85 \mathrm{~g} / \mathrm{dL}$, and c-reactive protein/albumin ratio $\geq 29$ were found to be risk factors for mortality. Based on the binary logistic regression analysis, age $\geq 85$ years, comorbidity $\geq 3$, and c-reactive protein/albumin ratio $\geq 29$ were independent predictors of mortality.

Conclusion: C-reactive protein/albumin ratio $\geq 29$ was a reliable indicator of mortality in elderly patients who underwent hemiarthroplasty for hip fractures. Additionally, being over the age of 85 and having three or more comorbidities was associated with an increased mortality risk.

Keywords: Hip Fractures; C - Reactive Protein; Aged 


\section{INTRODUCTION}

Hip fractures are a major public health problem and can lead to disability, reduced quality of life, and increased mortality. In general, hip fractures affect around 1.5 million people per year worldwide (1). The number of hip fractures will increase as the elderly population increases around the world. The high incidence of hip fractures combined with high morbidity and mortality rates has turned this into a social and economic burden (2).

Risk factors related to mortality have been the subject of numerous studies (3-6). Many risk factors related to geriatric hip fractures may affect mortality, including age, sex, functional ability before the fracture, type of fracture, type of surgery, preexisting comorbidities, duration of hospitalization, low preoperative hemoglobin, and high American Society of Anesthesiologists (ASA) score (3). Due to the high morbidity and mortality of hip fractures, more work must be done to resolve this issue and reduce the socioeconomic burden it creates.

Some studies have emphasized the importance of high c-reactive protein (CRP) and low albumin levels in hip fractures (4-6). However, there is no consensus on this subject, and studies on the relationship between the CRP/albumin ratio (CAR) and mortality are limited. Thus, this study aims to investigate the role of CAR in mortality after hip fractures. This research also seeks to clarify other risk factors related to mortality due to hip fractures.

\section{MATERIALS AND METHOD}

This observational study retrospectively reviewed the records of 144 patients over the age of 65 years who underwent hemiarthroplasty for hip fractures at the Abdurrahman Yurtaslan Oncology Training and Research Hospital from January 2015 to January 2018. Patients under 65 years of age, who died during or prior to surgery, or whose records could not be found were excluded from the study. Patients' age, sex, fracture type, ASA score, time between fracture and surgery (TFS), time between surgery and discharge (TSD), length of hospital stay, preexisting comorbidities, preoperative CRP and albumin levels, and mortality rates were recorded. Albumin value $(\mathrm{g} / \mathrm{dL})$ and CRP value $(\mathrm{mg} / \mathrm{L})$ measured in blood serum on day 0 after fracture were recorded.

Ethical approval was obtained from the ethics committee of our hospital to carry out this study. All procedures were done in accordance with the ethical standards of the institution's Human Experiment Committee and the Declaration of Helsinki. Informed consent was obtained from all participants or their family members.

\section{STATISTICAL ANALYSES}

Statistical analyses were done using SPSS for Windows, version 22.0 (IBM Corp., Armonk, NY, USA). Qualitative variables were expressed as frequencies and percentages and quantitative variables as medians and interquartile ranges (IQRs). The conformity of numerical data to a normal distribution was assessed using the Kolmogorov- Smirnov test. The Mann-Whitney $U$ test was used for comparative analyses of non-parametric variables between two independent groups, and the independent sample t-test was used for parametric variables. The chi-squared test and Fisher's exact test were used for comparative analyses of categorical variables between independent groups. To determine the optimum cut-off levels of pre-treatment albumin, CRP, CAR, TFS, and TSD, a receiver operating curve $(R O C)$ analysis was done. Following the ROC analysis, the area under the curve (AUC) for the cut-off values as well as their sensitivity and specificity were determined. A binary logistic regression model was used to determine the independent predictors of mortality. All statistical analyses were two way, and the level of statistical significance was set at $p<$ 0.05 . 


\section{RESULTS}

The median age of the 144 patients was 79 years (range: 65-101). Regarding sex, 89 patients (61.8\%) were female, and 55 patients (38.2\%) were male. The patients were divided into two groups survival and death for evaluation. Based on the univariate analysis, age, comorbidity, ASA score, TFS, TSD, CRP, al- bumin, and CAR were associated with mortality. The death group had a higher rate of older patients ( $\geq$ 85 years), patients with comorbidities $>3$, and ASA $\geq 4$ compared to the survival group. In addition, the median TFS, TSD, CRP, and CAR levels of the death group were higher than the survival group. Fracture type and sex were not found to be associated with mortality (Table 1).

Table 1. Patient Characteristics

\begin{tabular}{|c|c|c|c|c|}
\hline Characteristics & $\begin{array}{l}\text { Survival } \\
(n=69)\end{array}$ & $\begin{array}{c}\text { Death } \\
(n=75)\end{array}$ & $\begin{array}{c}\text { Total } \\
(n=144)\end{array}$ & $\mathbf{P}$ \\
\hline \multicolumn{5}{|l|}{ Gender, n (\%) } \\
\hline Female & $46(66.7)$ & $43(57.3)$ & $89(61.8)$ & \multirow{2}{*}{0.249} \\
\hline Male & $23(33.3)$ & $32(42.7)$ & 55 (38.2) & \\
\hline \multicolumn{5}{|l|}{ Age, n (\%) } \\
\hline $65-74$ & $26(37.7)$ & $8(10.7)$ & $34(23.6)$ & \multirow{3}{*}{$<0.001$} \\
\hline $75-84$ & $35(50.7)$ & $38(50.7)$ & $73(50.7)$ & \\
\hline$\geq 85$ & $8(11.6)$ & $29(38.7)$ & $37(25.7)$ & \\
\hline \multicolumn{5}{|l|}{ Comorbidity, n (\%) } \\
\hline$<3$ & $59(85.5)$ & $8(10.7)$ & $67(46.5)$ & \multirow{2}{*}{$<0.001$} \\
\hline$\geq 3$ & $10(14.5)$ & $67(89.3)$ & $77(53.5)$ & \\
\hline \multicolumn{5}{|l|}{ ASA, n (\%) } \\
\hline$<4$ & $58(84.1)$ & $33(44.0)$ & $91(63.2)$ & \multirow{2}{*}{$<0.001$} \\
\hline$\geq 4$ & $11(15.9)$ & $42(56.0)$ & $53(36.8)$ & \\
\hline \multicolumn{5}{|l|}{ Type of fracture, n (\%) } \\
\hline Neck & $32(46.4)$ & $24(32.0)$ & $56(38.9)$ & \multirow{3}{*}{0.204} \\
\hline Intertrochanteric & $36(52.2)$ & $50(66.7)$ & $86(59.7)$ & \\
\hline Subtrochanteric & $1(1.4)$ & $1(1.3)$ & $2(1.4)$ & \\
\hline TFS, median (Q1-Q3) & $1(1-2)$ & $2(1-4)$ & $1(1-3)$ & 0.036 \\
\hline TSD, median (Q1-Q3) & $5(4-6)$ & $6(4-11)$ & $5(4-9)$ & $<0.001$ \\
\hline Albumin (g/dL), median (Q1-Q3) & $2.8(2.6-3.0)$ & $2.6(2.4-2.8)$ & $2.7(2.5-2.9)$ & $<0.001$ \\
\hline CRP (mg/L), median (Q1-Q3) & $79(52-107)$ & $121(82-150)$ & $98(68-129)$ & $<0.001$ \\
\hline CAR, median (Q1-Q3) & $28.5(19.0-38.8)$ & $46.6(31.7-56.7)$ & $37.4(23.7-49.5)$ & $<0.001$ \\
\hline
\end{tabular}

ASA: American Society of Anesthesiologists; TFS: time between fracture and surgery; TSD: time between surgery and discharge; CRP: c-reactive protein; CAR: CRP/albumin ratio. 
Figure 1. $R O C$ analysis of $C R P$ and $C A R$

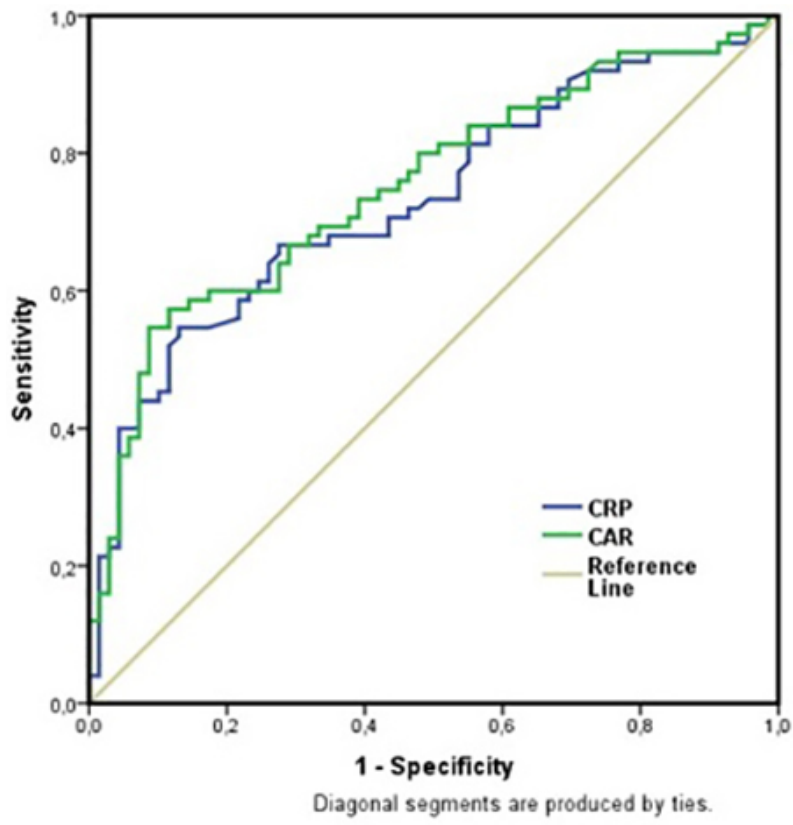

Based on the ROC analysis, the highest significant AUC value for the prediction of mortality was found for CAR (AUC = 0.752) followed by CRP (AUC $=0.731$ ) (Figure 1). The AUC values obtained for TFS (0.597), TSD (0.677), and albumin (0.704) were also found to be statistically significant (Figures 2ab; Table 2). The binary logistic regression analysis demonstrated that age $\geq 85$ years, comorbidities $\geq$
3 , and CAR $\geq 29$ were independent predictors of mortality (Table 3 ).

\section{DISCUSSION}

Hip fractures in the elderly population continue to be one of the most important issues in the health system, especially in orthopedics. Efforts are underway to solve this public health problem and to reduce the socio-economic burden it creates (3). The main finding of our study is that patients with three or more comorbidities, those over the age of 84 years, and those with a CAR value of 29 and above had a higher mortality rate.

Although the majority of research in the literature (7-11) recommends that hip fracture patients receive operations without delay to allow for early mobilization (thereby reducing mortality and morbidity), this topic remains controversial, and the effect of time between injury and surgery on mortality is debated. In a 2012 meta-analysis, Moja et al. (10) suggested that surgery should be performed within 2 days after fracture, and they reported more complications in delayed cases. Likewise, Anthony et al. (11) reported higher mortality in 4215 hip fracture patients with a surgical delay of more than 2 days. Similarly, in our study, a time between fracture and surgery of more than 2 days was associated with mortality rates. In addition, early fracture fixation

Table 2. ROC results

\begin{tabular}{l|c|c|c|c|c}
\hline Parameter & Cut-off & AUC (95\% Cl) & $\begin{array}{c}\text { Sensitivity } \\
\text { (\%) }\end{array}$ & $\begin{array}{c}\text { Specificity } \\
\text { (\%) }\end{array}$ & P \\
\hline TFS & 2.00 & $0.597(0.504-0.689)$ & 55 & 58 & 0.046 \\
\hline TSD & 5.00 & $0.677(0.589-0.765)$ & 75 & 49 & $<0.001$ \\
\hline Albumin & 2.85 & $0.704(0.619-0.789)$ & 81 & 42 & $<0.001$ \\
\hline CRP & 86.00 & $0.731(0.649-0.813)$ & 73 & 52 & $<0.001$ \\
\hline CAR & 29.00 & $0.752(0.672-0.831)$ & 80 & 51 & $<0.001$ \\
\hline
\end{tabular}

ROC: receiver operating curve; AUC: area under curve; Cl: confidence interval; TFS: time between fracture and surgery; TSD: time between surgery and discharge; CRP: c-reactive protein; CAR: CRP/albumin ratio. 
Figure 2. a: ROC analysis of the time between fracture and surgery, and time between surgery and discharge, b: ROC analysis of Albumin

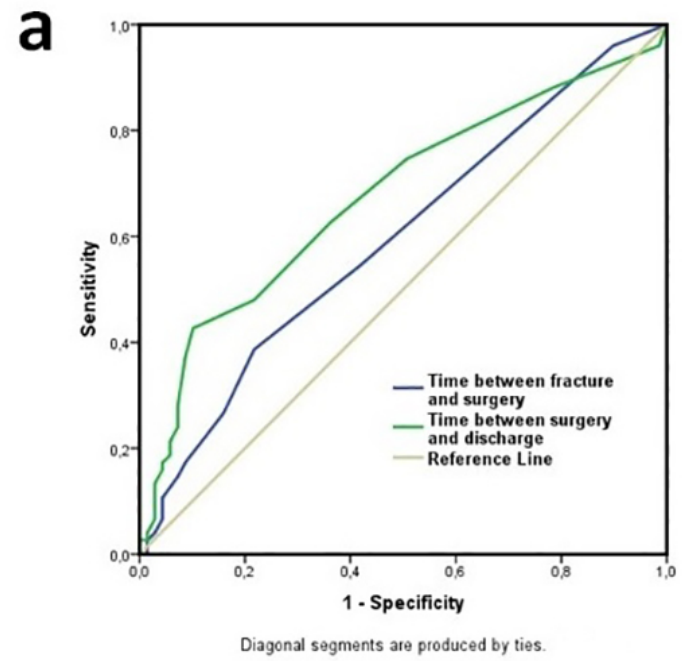

and mobilization of these patients decreases the economic burden by reducing the overall length of stay and thus the total cost of treatment (12).

CRP is a positive acute phase reactant that increases in the event of trauma, infection, or inflammation. Albumin, in contrast, is a negative acute phase reactant that decreases as a result of trauma, infection, or inflammation (13). Kim et al. (5) found a correlation for preoperative high CRP and preoperative low albumin levels with mortality in patients operated on for hip fractures. In their prospective study, Fakler et al. (14) showed that CRP is an independent predictive factor for mortality in hip fractures. Laulund et al. (15) demonstrated that low preoperative albumin levels are a prognostic factor for mortality. Capkin et al. (4) found that high CAR values are significantly correlated with mortality. In our study, while CAR was significant in the multivariate analysis, neither albumin alone nor CRP alone were significant. Thus, we propose that these values be evaluated together. High CRP and low serum albumin levels indicate impaired nutrition and provide information about the general condition of the pa-

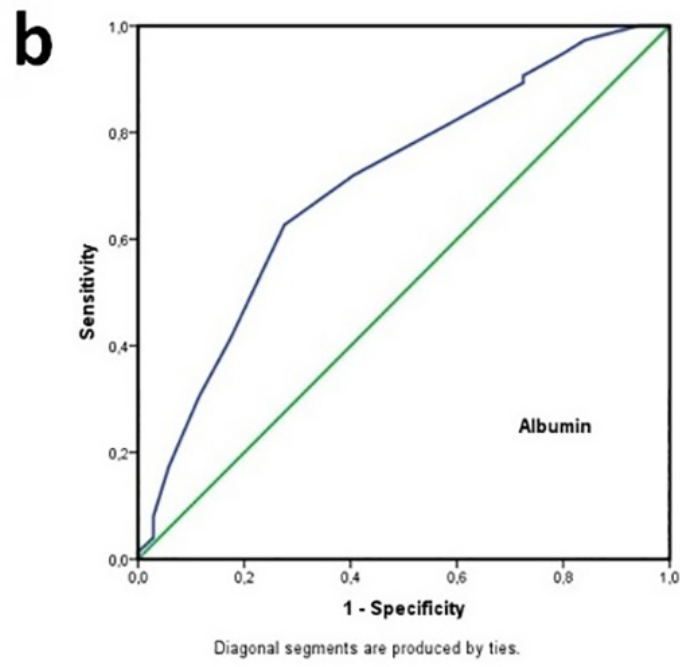

tient. Therefore, we think that high CAR values are associated with mortality.

Hu et al. (16) found an association for advanced age and high ASA score with mortality. Smith et al. (17) showed that patients over 85 years of age had a higher rate of mortality. Zuckerman et al. (18) showed that advanced age and high ASA score are predictive factors for mortality. Similarly, in our study, patients over the age of 85 and those with an ASA score of 4 or higher had a higher rate of mortality.

Jiang et al. (19) found a positive correlation between the number of comorbidities and mortality in patients operated on for hip fractures. Likewise, Zuckerman et al. (18) showed that comorbidity is a predictive factor for mortality. Panula et al. (20) found no relationship between hip fracture type and mortality in the elderly population. While there was no relationship between fracture type and mortality in our study, having three or more comorbidities was found to be a predictive factor for mortality.

Hip fractures are associated with increased mortality: $12 \%$ to $17 \%$ of patients with a hip fracture die 
Table 3. Independent predictors of mortality

\begin{tabular}{|c|c|c|}
\hline Parameter & OR $(95 \% \mathrm{Cl})$ & $\mathbf{P}$ \\
\hline \multicolumn{3}{|l|}{ Age } \\
\hline $65-74$ & Reference & \\
\hline $75-84$ & $3.40(0.83-13.92)$ & 0.089 \\
\hline$\geq 85$ & $11.52(1.86-71.23)$ & 0.009 \\
\hline \multicolumn{3}{|l|}{ Comorbidity } \\
\hline$<3$ & Reference & \\
\hline$\geq 3$ & $42.58(10.46-173.23)$ & $<0.001$ \\
\hline \multicolumn{3}{|l|}{ ASA } \\
\hline$<4$ & Reference & \\
\hline$\geq 4$ & $0.53(0.13-2.14)$ & 0.373 \\
\hline \multicolumn{3}{|l|}{ Albumin (g/dL) } \\
\hline$<2.85$ & Reference & \\
\hline$\geq 2.85$ & $0.47(0.14-1.61)$ & 0.230 \\
\hline \multicolumn{3}{|l|}{$\mathrm{CRP}(\mathrm{mg} / \mathrm{L})$} \\
\hline$<86$ & Reference & \\
\hline$\geq 86$ & $0.16(0.01-1.69)$ & 0.128 \\
\hline \multicolumn{3}{|l|}{ CAR } \\
\hline$<29$ & Reference & \\
\hline$\geq 29$ & $17.88(1.45-219.80)$ & 0.024 \\
\hline \multicolumn{3}{|l|}{ TFS } \\
\hline$\leq 2$ & Reference & \\
\hline$>2$ & $1.38(0.40-4.78)$ & 0.607 \\
\hline \multicolumn{3}{|l|}{ TSD } \\
\hline$\leq 5$ & Reference & \\
\hline$>5$ & $2.47(0.80-7.66)$ & 0.117 \\
\hline
\end{tabular}

OR: odds ratio; Cl: confidence interval; ASA: American Society of Anesthesiologists; CRP: c-reactive protein; CAR: CRP/albumin ratio; TFS: time between fracture and surgery; TSD: time between surgery and discharge.

within the first year, and the long-term increased risk of death is twofold (21). In Kim et al.'s (5) study, 1 -year mortality was found to be $14 \%$. Capkin et al. (4) found a 1-year mortality rate of $22 \%$. In parallel with these results, the 1-year mortality rate of our study was $21.5 \%$.
Women experience $80 \%$ of all hip fractures, and the average age at the time of fracture is 80 years (7). Almost all patients who experience a hip fracture are older than 65 years of age (7). Capkin et al.'s (4) study of hip fractures showed that the average age of the patients was 78 years, and $58 \%$ of the pa- 
tients were female. Similarly, the average age of the 144 patients examined in this study was 79 years, and $61.8 \%$ of the patients were women.

\section{Limitations}

This study has some limitations. First of all, it was a single-center retrospective study. In addition, although the population was statistically sufficient, the number of patients was still small. However, this study is valuable because of the categorization of numerous variables and their relationship with mortality.

\section{REFERENCES}

1. Cheng SY, Levy AR, Lefaivre KA, Guy P, Kuramoto L, Sobolev B. Geographic trends in incidence of hip fractures: a comprehensive literature review. Osteoporosint 2011;22(10):2575-86. (PMID: 21484361)

2. Abrahamsen B, Van Staa T, Ariely R, Olson M, Cooper $C$. Excess mortality following hip fracture: a systematic epidemiological review. OsteoporosInt 2009;20(10):1633-50. (PMID: 19421703)

3. Aslan A, Atay T, Aydoğan N H. Risk factors for mortality and survival rates in elderly patients undergoing hemiarthroplasty for hip fracture. ActaOrthopTraumatolTurc 2020;54(2):138-43. (PMID: 32254028)

4. Capkin S, Guler S, Ozmanevra R. C-reactive protein to albumin ratio may predict mortality for elderly population who undergo hemiarthroplasty due to hip fracture. J Invest Surg 2020;1-6 (PMID: 32668996)

5. Kim BG, Lee YK, Park HP, et al. C-reactive protein is an independent predictor for 1-year mortality in elderly patients undergoing hip fracture surgery: a retrospective analysis. Medicine 2016;95(43). (PMID: 27787371)

6. Symeonidis PD, Clark D. Assessment of malnutrition in hip fracture patients: effects on surgical delay, hospital stay and mortality. ActaOrthopBelg 2006;72(4):420 (PMID: 17009822)

7. Browner WS, Pressman AR, Nevitt MC, et al. Mortality following fractures in older women: the study of oste-

\section{CONCLUSION}

Hip fractures in the elderly population are one of the most important health issues today. A CAR $\geq$ 29 in patients who underwent hemiarthroplasty for hip fractures was a strong indicator for mortality. In addition, being over the age of 85 and having three or more comorbidities was associated with an increased mortality risk.

Disclosure statement: The authors declare no conflicts of interest.

oporotic fractures. Arch Intern Med 1996;156(14):15215. (PMID: 8687260)

8. Aqil A, Hossain F, Sheikh H, Aderinto J, Whitwell G, Kapoor $\mathrm{H}$. Achieving hip fracture surgery within 36 hours: an investigation of risk factors to surgical delay and recommendations for practice. J OrthopTraumatol 2016;17(3):207-13. (PMID: 26611677)

9. Sheehan KJ, Sobolev B, Guy P. Mortality by timing of hip fracture surgery: factors and relationships at play. J Bone Joint Surg Am 2017;99(20):e106. . (PMID: 29040134)

10. Moja L, Piatti A, Pecoraro V, et al. Timing matters in hip fracture surgery: patients operated within 48 hours have better outcomes. A meta-analysis and meta-regression of over 190,000 patients. PloS One 2012;7(10). (PMID: 23056256)

11. Anthony CA, Duchman KR, Bedard NA, et al. Hip fractures: appropriate timing to operative intervention. J Arthroplasty 2017;32(11):3314-8. (PMID: 28807469)

12. Siegmeth A, Gurusamy K, Parker M. Delay to surgery prolongs hospital stay in patients with fractures of the proximal femur. J Bone Joint Surg Br 2005;87(8):11236. (PMID: 16049251)

13. Bruserud $\varnothing$, Aarstad HH, Tvedt THA. Combined c-reactive protein and novel inflammatory parameters 
as a predictor in cancer: what can we learn from the hematological experience? Cancers 2020;12(7):1966. (PMID: 32707721)

14. Fakler JK, Grafe A, Dinger J, Josten C, Aust G. Perioperative risk factors in patients with a femoral neck fracture: influence of 25-hydroxyvitamin D and c-reactive protein on postoperative medical complications and 1-year mortality. BMC MusculoskeletDisord 2016;17(1):51. (PMID: 26833068)

15. Laulund AS, Lauritzen JB, Duus BR, Mosfeldt M, Jørgensen HL. Routine blood tests as predictors of mortality in hip fracture patients. Injury 2012;43(7):1014-20. (PMID: 26833068)

16. Hu F, Jiang C, Shen J, Tang P, Wang Y. Preoperative predictors for mortality following hip fracture surgery: a systematic review and meta-analysis. Injury 2012;43(6):676-85. (PMID: 21683355)

17. Smith T, Pelpola K, Ball M, Ong A, Myint PK. Pre-operative indicators for mortality following hip fracture surgery: a systematic review and meta-analysis. Age
Ageing 2014;43(4):464-71. (PMID: 24895018)

18. Zuckerman JD, Skovron ML, Koval KJ, Aharonoff G, Frankel VH. Postoperative complications and mortality associated with operative delay in older patients who have a fracture of the hip. J Bone Joint Surg Am 1995;77(10):1551-6. (PMID: 7593064)

19. Jiang HX, Majumdar SR, Dick DA, et al. Development and initial validation of a risk score for predicting inhospital and 1-year mortality in patients with hip fractures. J Bone Miner Res 2005;20(3):494-500. (PMID: 15746995)

20. Panula J, Pihlajamäki H, Mattila VM, et al. Mortality and cause of death in hip fracture patients aged 65 or older: a population-based study. BMC MusculoskeletDisord 2011;12(1):1-6. (PMID: 21599967)

21. Haentjens P, Magaziner J, Colón-Emeric CS, et al. Meta-analysis: excess mortality after hip fracture among older women and men. Ann Intern Med 2010;152(6):380-90. (PMID: 20231569) 